\title{
Trauma quality indicators: a way to identify attention points in the treatment of elderly trauma patients
}

\section{Filtros de qualidade: uma maneira de identificar pontos de atenção no atendimento ao idoso traumatizado}

Pedro de Souza lucarelli-Antunes ${ }^{1}$ (iD ; Luca Giovanni Antonio Pivetta²; José Gustavo Parreira, tCBC-SP1,2; José César Assef, TCBC-SP2.

\begin{abstract}
A B S T R A C T
Purpose: to trauma quality indicators as a tool to identify opportunities of improvement in elderly trauma patient's' treatment. Methods: prospective analysis of data collected between 2014-2015, and stored in the iTreg software (by Ecossistemas). Trauma victims, aged older than 60 years and trauma quality indicators were assessed, based on those supported by SBAIT in 2013: (F1) Acute subdural hematoma drainage after 4 hours from admission, in patients with $G C S<9 ;(F 2)$ emergency room transference without definitive airway and GCS $<9$; (F3) Re-intubation within 48 hours from extubation; (F4) Admission-laparotomy time greater than 60 min. in hemodynamically uinstable patients with abdominal bleeding; (F5) Unprogrammed reoperation; (F6) Laparotomy after 4 hours from admission; (F7) Unfixed femur diaphyseal fracture; (F8) Non-operative treatment for abdominal gunshot; (F9) Admission-tibial exposure fracture treatment time greater than 6 hours; (F10) Surgery after 24 from admission. The indicators, treatments, adverse effects and deaths were analyzed, using the SPSS software, and the chi-squared and Fisher tests were used to calculate the statistical relevance. Results: from the 92 cases, 36 (39,1\%) had complications and $15(16,3 \%)$ died. The adequate use of quality indicator's were substantially different among those who survived (was of $12 \%$ ) compared to those who died (55,6\%). The incidence of complications was of $77,8 \%(7 / 9)$ in patients with compromised indicators and $34,9 \%(28 / 83)$ in those without $(p=0.017)$. Conclusions: trauma quality indicators are directly related with the occurrence of complications and deaths, in elderly trauma patients.
\end{abstract}

Keywords: Traumatology. Multiple Trauma. Trauma Severity Indices. Quality of Health Care. Aged.

\section{INTRODUCTION}

$\mathrm{T}$ rauma constitutes a major public health problem, especially in large cities, corresponding to the third leading cause of death in the world ${ }^{1}$. It is a wellestablished pathological process, whose known and studied determinants of health and disease are targets of the main prevention campaigns.

Due to the increment in life expectancy, the number of traumatized elderly individuals has increased ${ }^{1-3}$. This age group brings specific difficulties in relation to pre-hospital care and diagnosis and treatment in the hospital environment ${ }^{4-8}$. This population is particularly subject to several social vulnerabilities that affect the patient's pre-trauma health status. Poor nutritional status, combined with a large number of associated chronic diseases, hinder the surgical management of trauma patients ${ }^{9}$. In addition, polypharmacy, a common practice among geriatric medical services in Brazil, increases the number of complications during the anesthetic induction, further worsening the prognosis of these patients in the trauma care service.

The current trend of systematizing trauma care with a focus on quality of care would lead to a faster, more efficient service, generating better therapeutic prognosis. Few studies, however, study the quality of

1 - Faculdade de Ciências Médicas da Santa Casa de São Paulo, Disciplina de Cirurgia - São Paulo - SP - Brasil 2 - Irmandade da Santa Casa de Misericórdia de São Paulo, Serviço de Emergência - São Paulo - SP - Brasil 
care of trauma patients, especially the elderly ones. In view of this, the analysis of the impact of quality of care on patients' prognosis becomes relevant.

Thus, this study aims to evaluate the usefulness of variables considered as quality indicators and idealized by the American College of Surgeons as indicative of key points of care to the traumatized elderly, aiming at improving prognosis and treatment effectiveness at a Specialized Traumatized Care Service.

\section{METHODS}

This study was submitted to the Ethics in Research Committee of the institution and approved under number 656.666. We held a retrospective analysis of Trauma Registry data, selecting patients with age greater than or equal to 60 years, admitted between 2014 to 2015 (12 months) in the Emergency Service of the Brotherhood of the Santa Casa de Misericordia de São Paulo.

\section{Database}

The records of trauma patients belong to the Registry of the Emergency Service Trauma of the Brotherhood of the Santa Casa de Misericórdia de São Paulo, being part of the Traumatized Assistance Quality Program. Data are collected in the Emergency Room and during the hospitalization of trauma patients assisted by the Surgery Department. Data are stored in a software specifically developed for this purpose, the iTreg (Ecossistemas).

\section{Data analysis}

We reviewed data from trauma victims whose information were present on the database. The inclusion criteria for the search were the presence of traumatic injury in patients over 60 years. We analyzed age, sex, trauma mechanism, associated diseases, injuries found, treatment and mortality. We recorded the presence or absence of compromised quality indicators (QIs) in the patients' treatment.

QIs are pre-established variables used for identification of groups of patients in which flaws in the process are more frequent. Based on the indicators devised by the American College of Surgeons ${ }^{10}$ and the Brazilian Society for Integral Assistance to the Traumatized (SBAIT) in 2013, we suggest the analysis of the following variables:

1. (F1) Acute subdural hematoma drainage after 4 hours of admission in patients with Glasgow Coma Scale (GCS) < 9;

2. (F2) Transfer from the emergency room without definitive airway and GCS $<$ 9;

3. (F3) Reintubation within 48 hours of extubation;

4. (F4) Time between admission and exploratory laparotomy greater than 60 minutes in unstable patients with abdominal focus;

5. (F5) Unscheduled reoperation;

6. (F6) Laparotomy after 4 hours of admission;

7. (F7) Non-fixed femoral diaphysis fracture;

8. (F8) Non-operative treatment of abdominal gunshot wound;

9. (F9) Time between admission and treatment of exposed tibial fractures greater than 6 hours;

10. (F10) Operation after 24 hours of admission.

We studied the relationship between the nonobservance of the quality indicators and demographic data, identified injuries, treatments, complications, and deaths. For the purposes of statistical analysis, the severity of injuries was based on pre-established indexes, stratified by the Anatomical Injury Score (AIS) ${ }^{11}$ and the Injury Severity Score (ISS) ${ }^{12}$. According to the injuries' nature, we chose the AIS as the standard for determining severity. The AIS comprises a list of several injuries stratified by body segment and severity. Didactically, it divides the organism into six segments: head and neck; face; chest; abdomen/pelvis; extremities and pelvic ring; and general or external. According to the severity of the injury, it receives a score, 1 for mild injuries, 2 for moderate ones, 3 for severe injuries with no imminent risk of death, 4 for those that are severe and bring imminent risk of life, 5 for critical lesions with doubtful survival, and 6 for those that are almost always fatal ${ }^{11}$. This score standardizes the terminology in the evaluation of the traumatized person, in addition to providing the ability to stratify injuries based on anatomical location. 
We performed the statistical analysis using the Student's t, the Chi-square, and the Fisher tests, given the qualitative nature of the variables evaluated, with $p$ $<0.05$ deemed significant. We considered injuries with AIS $\geq 3$ to be severe.

\section{RESULTS}

We selected 92 cases, with a mean age of 75.9 \pm 10.0 years (range 61-102). As for chronic diseases, patients presented hypertension (52.2\%), diabetes mellitus $(16.3 \%)$, chronic obstructive pulmonary disease (3.3\%), and previous stroke (3.3\%).

Regarding the mechanism of trauma, there were 45 cases of fall from standing height, 19 runoffs, 19 falls from height, five assaults, two stabbing injuries, and two cases classified as "other mechanisms". The ISS ranged from one to 50 (Table 1), with an average of $6.8 \pm 10.1$. Some type of complication affected $39.1 \%$ of patients (36), and the mortality rate was $16.3 \%$ (15 deaths).

Table 1. Quality filter adoption. Patients'stratification according to the scored ISS and its relation to the injuries.

ISS

\begin{tabular}{cc}
\hline $0-8$ & $68 / 92(73.3 \%)$ \\
$9-15$ & $6 / 92(6.6 \%)$ \\
$16-25$ & $9 / 92(9.9 \%)$ \\
Greater than 25 & $9 / 92(9.9 \%)$
\end{tabular}

Regarding the analysis of the proposed variables, the nonobserved quality indicators were: (F1) acute subdural hematoma drainage after 4 hours of admission in patients with GCS < 9; (F2) transfer from the emergency room without definitive airway and GCS $<$ 9; (F3) reintubation within 48 hours of extubation; (F6) laparotomy after 4 hours of admission; and (F10) operation after 24 hours of admission.
Nine patients (9.78\%) had some nonobserved quality indicator. Operation after 24 hours of admission to the service was the most frequent (four patients), half of which occurred in patients with some type of complication. Transfer from the emergency room without a definitive airway and GCS $<9$, reintubation within 48 hours of extubation, and laparotomy after 4 hours of admission occurred only in complicated patients. Thus, there were three (F1) compromises, one in an uncomplicated patient and two in complicated patients, two (F2), two (F3), one (F6), and four (F10). Three patients had two simultaneously compromised QIs.

The comparative analysis of the incidence of adverse events occurring during hospitalization of traumatized elderly individuals varied according to the frequency of non-compliance with the quality indicators. The incidence of complications during hospitalization in patients who had a compromised QI was 77.8\% (7/9), which fell to less than half $(p=0.017)$, reaching $34.9 \%(28 / 83)$ in patients who evolved without any such breach. The same occurred when analyzing deaths. The frequency of nonobserved QIs was 33.3\% (5/15) in those patients who died, while being $5.2 \%(4 / 77)$ in the patients who survived ( $p=0.005)$ ( Graph 1 ).

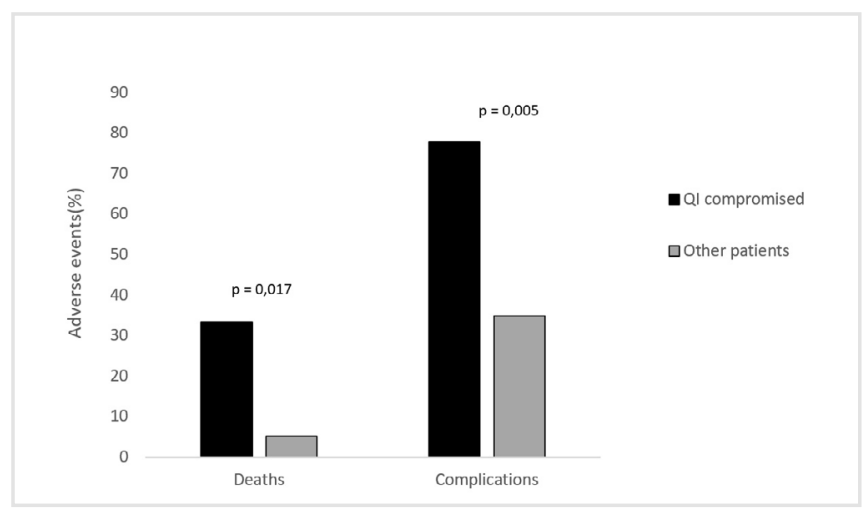

Graphic 1. Outcome assessment. Incidence of death and complications comparing those patients who had a quality factor to those who did not have it.

Upon comparative analysis of compromised QIs according to the proposed ISS stratification, we observed that they only occurred in patients with ISS greater than 9, with one case in the range 9-15, four in the range $16-25$, and four in patients with ISS greater than 25 . The 
difference in the incidence of QI breaches between the patients' groups was statistically significant $(p<0.001)$ (Graph 2).

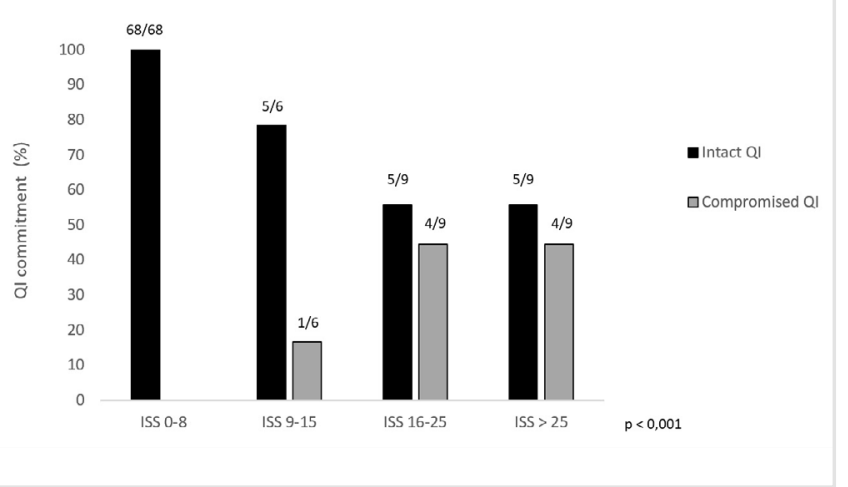

Graphic 2. Stratified analysis of quality filter adoption by disease severity. Incidence of non-adoption of any quality filter according to the ISS.

\section{DISCUSSION}

Trauma in the elderly is a well-established clinical entity. According to the literature, the highest incidence of trauma in the elderly is represented by falls and runoffs $7,13-15$, a fact corroborated by the patients' results in this study. Compromised QIs are mostly related to the time between the admission and the appropriate therapeutic conduct. This fact denotes that speed and assertiveness are essential in the elderly trauma patient, considering that a longer time under the trauma stress determines a higher consumption of already depleted reserves.

The quality indicators were originally recommended to evaluate the hospitalization process of patients admitted in the emergency department, seeking flaws in the process and the optimization of procedures and expenses, eminently functioning as a management tool for the hospital service. However, the usefulness from a clinical point of view has not been well explored so far. The purpose of the analysis proposed here is, therefore, to demonstrate its utility in determining prognosis, especially among the elderly. This group of particular vulnerability has been increasingly admitted to emergency rooms, either due to demographic growth or due to changes in the patterns of trauma health-disease determinants.

In our sample, we verified that the mortality rate was significant $(16.3 \%)$, in agreement with the fragility of this age group and denoting that one should show especial concern towards this population in specialized trauma services ${ }^{16,17}$.

Around $10 \%$ of patients had some nonobserved quality indicator, particularly patients with more severe lesions, this group requiring special attention. Considering the lower physiological reserve inherent to age and the comorbidities that accompany this state ${ }^{18,19}$, the nonobservance of quality indicators can be decisive for the poor prognosis of the traumatized elderly. This was demonstrated by the rate of complications and mortality in this group when compared with the control, QI-compliant one.

The incidence of complications during hospitalization of the traumatized elderly dropped by a half when QIs were respected. Moreover, the death rate was one sixth lower among patients with QI compliance compared with those who had nonobserved QIs. This fact suggests that the proposed variables are associated with more serious injuries, having clinical relevance and allowing their use during hospitalization to influence the management of traumatized elderly patients, aiming at early discharge and greater treatment effectiveness. This happens because their occurrence determines a greater probability of the patient having adverse events, either due to failures in care or due to the complexity of the lesions, which require clinical and/or surgical management, to such an extent that they even lead more frequently to death.

From the analyzed data, we conclude that quality indicators are good parameters to assess the quality of care to the traumatized elderly. The compromise of quality indicators is directly related to the occurrence of complications and death in elderly trauma patients, representing special attention points due to being predictors of poor prognoses in urgent care. Thus, we suggest that Qls be implemented in services that care for traumatized elderly individuals, not only from an administrative perspective, reducing expenses, but also from a clinical point of view, as a way to reduce morbidity and mortality of trauma patients. 
Objetivo: analisar a utilidade de "filtros de qualidade" pré-estabelecidos para a identificação de oportunidades de melhora no atendimento ao idoso traumatizado. Método: análise prospectiva dos dados coletados entre 2014-2015 e armazenados em software iTreg (Ecossistemas). Foram revisados vitimas de trauma maiores de 60 anos e filtros de qualidade propostos, baseados naqueles idealizados pela SBAIT em 2013: (F1) Drenagem de hematoma subdural agudo após 4 horas da admissão em pacientes com ECG<9; (F2) transferência da sala de emergência sem via aérea definitiva e ECG<9; (F3) Reintubação em até 48 horas da extubação; (F4) Tempo admissão-laparotomia exploradora maior que 60 min. em pacientes instáveis com foco abdominal; (F5) Reoperação não programada; (F6) Laparotomia após 4 horas da admissão; (F7) Fratura de diáfise de fémur não fixada; (F8) Tratamento não operatório de ferimento abdominal por PAF; (F9) Tempo admissão-tratamento de fraturas expostas de tíbia superior a 6 horas; (F10) Operação após 24 horas da admissão. Foi analisada relação dos filtros com tratamentos, complicações e óbitos, pelo software SPSS, utilizandose o teste qui-quadrado e Fisher para calcular a relevância estatística. Resultados: dos 92 casos, 36 (39, 1\%) tiveram complicações e $15(16,3 \%)$ morreram. A frequência da quebra dos filtros foi de $12 \%$ em pacientes que sobreviveram e $55,6 \%$ nos entre os que faleceram ( $p=0,005)$. A incidência de complicações foi de $77,8 \%$ (7/9) nos em doentes com FQ comprometido, contra 34,9\% (28/83) nos não comprometidos $(p=0,017)$. Conclusões: o comprometimento dos filtros de qualidade se relaciona diretamente com a ocorrência de complicações e óbitos em idosos traumatizados.

Palavras chave: Traumatologia. Traumatismo Múltiplo. Índices de Gravidade do Trauma. Qualidade da Assistência à Saúde. Idoso.

\section{REFERENCES}

1. Parreira JG, Matar MR, Tôrres ALB, Perlingeiro JAG, Solda SC, Assef JC. Análise comparativa entre as lesões identificadas em vítimas de queda de altura e de outros mecanismos de trauma fechado. Rev Col Bras Cir. 2014;41(4):272-7.

2. Meldon SW, Reilly M, Drew BL, Mancuso C, Fallon W Jr. Trauma in the very elderly: a community-based study of outcomes at trauma and nontrauma centers. J Trauma. 2002;52(1):79-84.

3. Joseph B, Zangbar B, Pandit V, Fain M, Mohler MJ, Kulvatunyou $\mathrm{N}$, et al. Emergency general surgery in the elderly: too old or too frail? J Am Coll Surg. 2016;222(5):805-13.

4. Tornetta P, Mostafavi H, Riina J, Turen C, Reimer $B$, Levine $R$, et al. Morbidity and mortality in elderly trauma patients. J Trauma. 1999;46(4):702-6.

5. Parreira JG, Farrathl S, Soldá SC, Perlingeiro JAG, Assef JC. Análise comparativa das características do trauma entre idosos com idade superior e inferior a 80 anos. Rev Col Bras Cir. 2013;40(4):269-74.

6. van Geloven AA, Biesheuvel TH, Luitse JS, Hoitsma $\mathrm{HF}$, Obertop H. Hospital admissions of patients aged over 80 with acute abdominal complaints. Eur J Surg. 2000;166(11):866-71.

7. Adams SD, Cotton BA, McGuire MF, Dipasupil E, Podbielski JM, Zaharia A, et al. Unique pattern of complications in elderly trauma patients at a
Level I trauma center. J Trauma Acute Care Surg. 2012;72(1):112-8.

8. Zhao FZ, Wolf SE, Nakonezny PA, Minhajuddin A, Rhodes RL, Paulk $M E$, et al. Estimating geriatric mortality after injury using age, injury severity, and performance of a transfusion: the geriatric trauma outcome score. J Palliat Med. 2015;18(8):677-81.

9. Orouji Jokar $T$, Ibraheem $K$, Rhee $P$, Kulavatunyou $\mathrm{N}$, Haider $\mathrm{A}$, Phelan HA, et al. Emergency general surgery specific frailty index: a validation study. J Trauma Acute Care Surg. 2016;81(2):254-60.

10. American College of Surgeons. Resources for Optimal Care of the Injured Patient: 2006. Chicago: Committee on Trauma, American College of Surgeons; 2006.

11. Association for Advancement of Automotive Medicine. The abbreviated injury scale. Des Plaines, IL: Association for Advancement of Automotive Medicine; 1990.

12. Baker SP, O'Neil B, Haddon W Jr, Long WB. The injury severity score: a method for describing patients with multiple injuries and evaluating emergency care. J Trauma. 1974;14(3):187-96.

13. Spaniolas K, Cheng JD, Gestring ML, Sangosanya A, Stassen NA, Bankey PE. Ground level falls are associated with significant mortality in elderly patients. J Trauma. 2010;69(4):821-5.

14. Bergeron E, Clement J, Lavoie A, Ratte S, Bamvita JM, Aumont $F$, et al. A simple fall in the elderly: not so simple. J Trauma. 2006;60(2):268-73. 
15. Hruska K, Ruge T. The Tragically Hip: Trauma in Elderly Patients. Emerg Med Clin North Am. 2018;36(1):21935.

16. Kanezaki S, Miyazaki M, Notani N, Tsumura H. Clinical presentation of geriatric polytrauma patients with severe pelvic fractures: comparison with younger adult patients. Eur J Orthop Surg Traumatol. 2016;26(8):885-90.

17. Ohmori T, Kitamura T, Tanaka K, Saisaka Y, Ishihara J, Onishi $\mathrm{H}$, et al. Bleeding sites in elderly trauma patients who required massive transfusion: a comparison with younger patients. Am J Emerg Med. 2016;34(2):1237.

18. Newgard CD, Holmes JF, Haukoos JS, Bulger EM, Staudenmayer $K$, Wittwer $L$, et al. Improving early identification of the high-risk elderly trauma patient by emergency medical services. Injury. 2016; 47(1):1925.

19. Ohmori $T$, Kitamura $T$, Ishihara J, Onishi $H$, Nojima T, Yamamoto $K$, et al. Early predictors for massive transfusion in older adult severe trauma patients. Injury. 2017;48(5):1006-12.
Received in: 19/03/2020

Accepted for publication: 08/05/2020

Conflict of interest: no.

Funding source: none.

\section{Mailing address:}

Pedro de Souza Lucarelli-Antunes

E-mail: lucarelli_2007@yahoo.com.br

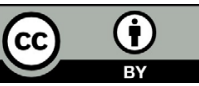

